\title{
AVALIAÇÃO DE SUBSTRATOS E TEMPERATURAS PARA SEMENTES DE ESPÉCIES FLORESTAIS
}

\author{
Sergio Roberto Garcia dos SANTOS ${ }^{1}$ \\ Ana Cecília Florêncio BEZERRA ${ }^{2}$ \\ Paulo Gabbai Monteiro de OLIVEIRA ${ }^{3}$ \\ Sebastiana Dutra Souza Revoredo da SILVA ${ }^{4}$ \\ Rinaldo César de PAULA ${ }^{5}$
}

${ }^{1}$ Pesq. Cient., Instituto Florestal, escunagarcia@if.sp.gov.br

${ }^{2}$ Bióloga, acfb.bio@gmail.com

${ }^{3}$ Biólogo, paulogabbai@hotmail.com

${ }^{4}$ Técnica de laboratório, Instituto Florestal, tiana12dutra12@gmail.com

${ }^{5}$ Professor, UNESP/Jaboticabal, rcpaula@ fcav.unesp.br

Recebido em: 05/11/2014 - Aprovado em: 03/06/2015 - Disponibilizado em: 15/07/5

RESUMO: Este trabalho teve por objetivo avaliar diferentes substratos e temperaturas, de uso em laboratório, com sementes de: Astronium graveolens (guaritá), Cedrela fissilis (cedro) e Cytharexyllum myrianthum (pau-viola). Foram testados as temperaturas de 25 e $20-30{ }^{\circ} \mathrm{C}$ e os substratos: sobre areia (SA), sobre papel (SP), sobre vermiculita (SV), entre areia (EA), entre papel (EP) e entre vermiculita (EV). O ensaio, por espécie, foi inteiramente casualizado sob o esquema fatorial de 2 × 6 (duas temperaturas e seis substratos) e a comparação entre as médias foi pelo Teste de Tukey (5\%). Tendo como resultados: para o guaritá não houve diferença entre as temperaturas e os melhores substratos foram: SA, SV, EA, EV e EP; para o cedro, a melhor temperatura foi $25^{\circ} \mathrm{C}$ quando considerada a velocidade de germinação (IVG) e não houve diferenciação entre substratos e para o pau-viola, não houve diferenciação entre temperaturas e os melhores substratos foram SP e SA quando analisado o IVG.

Palavras-chave: germinação. análise. laboratório. viabilidade. nativas.

\section{EVALUATION OF SUBSTRATES AND TEMPERATURES TO SEEDS OF FOREST SPECIES}

ABSTRACT:This study aimed to evaluate different substrates and temperatures, laboratory use, with seeds: Astronium graveolens (guaritá) Cedrela Cedrela (cedro) and Cytharexyllum myrianthum (pau-viola). Temperatures of 25 and $20-30{ }^{\circ} \mathrm{C}$ and the substrates were tested: on sand (SA), on paper (SP), on vermiculite (SV) between sand (EA) between paper (EP) and between vermiculite (EV). The essay, by species, was completely randomized in a factorial scheme $2 \times 6$ (six temperatures and two substrates) and the comparison between the means was by Tukey test (5\%). Having results as: not to guaritá was no difference between the temperatures and the best substrates were: SA, SV, EA, EV and EP; for the cedro, the best temperature was $25^{\circ} \mathrm{C}$ when considering the speed of germination (IVG) and there was no differentiation between substrates and for pau-viola, there was differentiation between temperatures and the best substrates SP and SA were analyzed when the IVG.

Keywords: germination. analysis. laboratory. viability. native. 


\section{INTRODUÇÃO}

$O$ teste de germinação realizado em laboratório deve refletir o potencial máximo de germinação do lote de sementes (FERRAZ; CALVI, 2010) e para as espécies florestais nativas há ainda muito pouca informação na literatura sobre a metodologia destes testes e que atendam as exigências das sementes (MEDEIROS; ABREU, 2005; LIMA JUNIOR, 2010).

O substrato e a temperatura são dois importantes fatores que afetam o comportamento germinativo das sementes durante o teste de germinação (SANTOS; AGUIAR, 2000).

A temperatura tem influência tanto no total de sementes germinadas quanto na determinação do vigor das plântulas, interferindo também na absorção de água pela semente e nas reações bioquímicas que regulam todo o processo metabólico (CARVALHO; NAKAGAWA， 2000; ALVES et al., 2002; BEWLEY; BLACK, 1994 apud PACHECO et al., 2006).

As sementes, frente a esse fator, apresentam comportamento variável não havendo uma temperatura ótima e uniforme para todas as espécies; a faixa de 20 a $30{ }^{\circ} \mathrm{C}$ tem sido adequada para grande número de espécies subtropicais e tropicais (BORGES; RENA, 1993), além da constante de $25^{\circ} \mathrm{C}$, comumente utilizada em germinadores de laboratórios de análise de sementes (MONDO et al., 2010).

O substrato tem a função de suprir as sementes de umidade e proporcionar as condições adequadas à sua germinação e ao posterior desenvolvimento das plântulas (FIGLIOLIA et al., 1993), uma vez que fatores como estrutura, aeração, capacidade de retenção de água, grau de infestação de patógenos podem variar de acordo com o tipo de material utilizado (POPINIGIS, 1977). A sua escolha deve ser feita levando-se em consideração algumas características da semente como tamanho, facilidade ou não para realização das contagens e avaliação das plântulas e exigências com relação à quantidade de água e sensibilidade à luz (BRASIL, 2009).

O objetivo deste trabalho foi estudar o efeito do substrato e da temperatura na germinação das sementes de Astronium graveolens, Cedrela fissilis e Cytharexyllum myrianthum, visando subsidiar os testes de laboratório e contribuir para o entendimento ecofisiológico destas espécies em seus locais de ocorrência.

\section{MATERIAL E MÉTODOS}

As sementes das espécies utilizadas neste estudo, Astronium graveolens, Cedrela fissilis e Cytharexyllum myrianthum, estavam armazenadas, antes da realização do ensaio, em câmaras frias, com $10{ }^{\circ} \mathrm{C}$ e umidade relativa de $90 \%$. A metodologia descrita 
abaixo, é a mesma utilizada para as três espécies florestais.

Antes da montagem dos ensaios foi realizada a determinação do teor de água das sementes em estufa à $105{ }^{\circ} \mathrm{C}$ por 24 horas (BRASIL, 2009), com duas repetições de 25 sementes.

Um pré-tratamento para a desinfecção das sementes foi utilizado. As sementes foram imersas por dez minutos em uma solução a $2 \%$ de hipoclorito de sódio, e em seguida lavadas com água destilada por três vezes.

$\mathrm{Na}$ montagem do ensaio as sementes foram semeadas nas modalidades entre e sobre substrato (areia, vermiculita e papel filtro) e colocadas em dois germinadores. Um regulado para a temperatura de $25^{\circ} \mathrm{C}$ e o outro para $20-30{ }^{\circ} \mathrm{C}$, ambos sob o fotoperíodo de oito horas de luz branca.

Os tratamentos foram distribuídos em caixas do tipo gerbox, sendo cada um constituído de quatro repetições de 25 sementes. A germinação foi avaliada diariamente, observando-se a emergência da radícula, em torno de $0,5 \mathrm{~cm}$, como critério botânico de germinação (LABORIAU, 1983).

Os parametros analisados foram a porcentagem e o índice de velocidade de germinação (IVG), este último um teste de vigor e determinado através de fórmula proposta por Maguire (1962).

O delineamento experimental adotado, para cada espécie, na análise dos dados, foi o inteiramente casualizado sob o esquema fatorial de $2 \times 6$ (duas temperaturas $\mathrm{x}$ seis substratos). Os dados percentuais nas análises foram transformados em arco seno; nas tabelas, entretanto, os resultados são apresentados sem transformação. A comparação entre as médias dos tratamentos foi feita pelo Teste de Tukey, em nível de 5\% de probabilidade.

\section{RESULTADOS E DISCUSSÃO}

Os teores de água obtidos para as três espécies, foram de 9,88\% para o guaritá (Astronium graveolens); 6,72\% para o cedro (Cedrela fissilis) e de 8,35\% para pau-viola (Cytharexyllum myrianthum) e estão de acordo com os valores esperados para o armazenamento em câmara fria.

Dos resultados observados para o guaritá, Tabela 1, os dados referentes à germinação mostram que na média não houve diferenciação entre as duas temperaturas, bem como para os substratos testados.

Para os valores de IVG, Tabela 1, temse um resultado diferente para os substratos. A semeadura sobre papel apresentou valores inferiores aos obtidos pelas sementes semeadas entre substatos (areia, papel de filtro e vermiculita), embora estes últimos sejam equivalentes a semeaduara sobre areia e sobre vermiculita. Quanto à temperatura, do mesmo modo que a germinação, não se tem diferenciação entre elas. 
Tabela 1. Germinação (\%) e índice de velocidade de germinação (IVG) de sementes de Astronium graveolens (guaritá) submetidas a duas temperaturas (25 e $20-30{ }^{\circ} \mathrm{C}$ ) e seis substratos*.

\begin{tabular}{|c|c|c|c|c|c|c|}
\hline \multirow[b]{2}{*}{ Tratamentos } & \multicolumn{3}{|c|}{$\% \mathrm{G}$} & \multicolumn{3}{|c|}{ IVG } \\
\hline & $25^{\circ} \mathrm{C}$ & $20-30^{\circ} \mathrm{C}$ & Média & $25^{\circ} \mathrm{C}$ & $\begin{array}{c}20-30 \\
{ }^{\circ} \mathrm{C}\end{array}$ & Média \\
\hline SA & 61 & 69 & $65 \mathrm{~A}$ & 5,11 & 5,26 & $5,19 \mathrm{AB}$ \\
\hline SV & 81 & 69 & $75 \mathrm{~A}$ & 5,91 & 3,98 & $4,95 \mathrm{AB}$ \\
\hline SP & 70 & 71 & $71 \mathrm{~A}$ & 4,32 & 3,83 & $4,08 \mathrm{~B}$ \\
\hline EA & 71 & 65 & $68 \mathrm{~A}$ & 6,36 & 5,83 & $6,10 \mathrm{~A}$ \\
\hline $\mathrm{EV}$ & 68 & 78 & $73 \mathrm{~A}$ & 6,09 & 6,3 & $6,20 \mathrm{~A}$ \\
\hline EP & 73 & 70 & $72 \mathrm{~A}$ & 6,92 & 6,13 & $6,53 \mathrm{~A}$ \\
\hline Média & $71 \mathrm{a}$ & $70 \mathrm{a}$ & & $5,79 \mathrm{a}$ & $5,22 \mathrm{a}$ & \\
\hline \multicolumn{4}{|c|}{$\begin{array}{l}\% \mathrm{G} \text { - Fator A (temperatura): } 0,03 \mathrm{~ns} ; \\
\text { Fator B (substrato): } 0,97 \mathrm{~ns} \text {; Fator A x } \\
\text { B: } 1,48 \mathrm{~ns} ; \mathrm{CV}: 12,45 \%\end{array}$} & 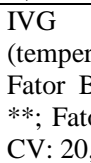 & $\begin{array}{l}-\mathrm{Fa} \\
\text { atura): } \\
\text { (substra } \\
\text { or A x B } \\
51 \%\end{array}$ & $\begin{array}{l}\text { tor } \quad \mathrm{A} \\
2,99 \mathrm{~ns} \text {; } \\
\text { to): } 5,42 \\
0,96 \mathrm{~ns} \text {; }\end{array}$ \\
\hline \multicolumn{7}{|c|}{$\begin{array}{l}\text { ns - valor não significativo pelo teste } \mathrm{F} \text { a } 5 \% \text { de probabilidade. } \\
\text { Médias seguidas pela mesma letra minúscula, na linha, e maiúscula, } \\
\text { na coluna, não diferem entre si pelo teste Tukey a } 5 \% \text { de } \\
\text { probabilidade. CV- coeficiente de variação. *Substratos: SV- sobre } \\
\text { vermiculita; SP- sobre papel; SA- sobre areia; EV- entre vermiculita; } \\
\text { EP- entre papel e EA- entre areia. }\end{array}$} \\
\hline
\end{tabular}

A interação entre os fatores temperatura e substrato não foi significativa para os dois parametros estudados. Com relação aos valores obtidos para o coeficiente de variação (CV), observa-se que seus resultados estão dentro de uma faixa de valores, que são considerados médios (de $10 \mathrm{a}$ 20\%) segundo Gomes (1987). Deste modo, embora os ensaios tenham sido conduzidos em laboratório com uma preocupação na realização da amostragem e homogenização das sementes, para as espécies nativas em razão de não se ter um trabalho de melhoramento (para a grande maioria), é de se esperar uma maior variação nos valores de germinação e IVG, em razão de uma maior variabilidade na morfologia e fisiologia de suas sementes (WIELEWICKI et al., 2006) quando comparado com as espécies agrícolas.
Os resultados de germinação obtidos com as sementes de pau-viola, apresentados na Tabela 2, mostram que não houve diferença entre as temperaturas testadas, mas para os substratos observa-se que a semeadura sobre areia foi superior estatisticamente áquela apresentada quando as sementes foram colocadas entre areia. Os outros substratos foram equivalentes, quanto aos valores de germinação, em relação ao tratamento sobre areia.

Com relação aos resultados médios de IVG para as sementes de pau-viola, Tabela 2, os valores das duas temperaturas não se diferenciaram, enquanto que para os substratos a semeadura sobre areia foi equivalente à sobre papel e a primeira superior as demais.

No ensaio com as sementes de $C$. myrianthum, não houve interação entre temperatura e substrato, tanto para germinação como para o IVG, indicando que um fator não influiu sobre o outro. Para o coeficiente de variação (CV), os dados de germinação tiveram um valor de 13,33\% e para IVG, 17,50\%, ambos sendo considerados médios de acordo com Gomes (1987). 
Tabela 2. Germinação (\%) e índice de velocidade de germinação (IVG) de sementes de Cytharexyllum myrianthum (pau-viola) submetidas a duas temperaturas $\left(25\right.$ e $\left.20-30{ }^{\circ} \mathrm{C}\right)$ e seis substratos*.

\begin{tabular}{|c|c|c|c|c|c|c|}
\hline \multirow{2}{*}{ Tratamentos } & \multicolumn{3}{|c|}{$\% \mathrm{G}$} & \multicolumn{3}{|c|}{ IVG } \\
\hline & $25^{\circ} \mathrm{C}$ & $20-30^{\circ} \mathrm{C}$ & Média & $25^{\circ} \mathrm{C}$ & $20-30^{\circ} \mathrm{C}$ & Média \\
\hline SV & 80 & 67 & $74 \mathrm{AB}$ & 1,26 & 1,06 & \\
\hline $\mathrm{P}$ & 76 & 72 & $74 \mathrm{AB}$ & 1,48 & 24 & $1,36 \mathrm{AB}$ \\
\hline A & 77 & 81 & 79 A & 1,68 & & \\
\hline V & 74 & 69 & $72 \mathrm{AB}$ & 1,2 & 1,14 & $1,17 \mathrm{~B}$ \\
\hline EP & 74 & 64 & $69 \mathrm{AB}$ & 1,4 & 1,21 & $\mathrm{~B}$ \\
\hline EA & 53 & 65 & $59 \mathrm{~B}$ & 0,8 & 0,77 & $\mathrm{C}$ \\
\hline & $72 \mathrm{a}$ & $70 \mathrm{a}$ & & $1,30 \mathrm{a}$ & $1,15 \mathrm{a}$ & \\
\hline \multicolumn{7}{|c|}{$\begin{array}{ll}\% \mathrm{G} \text { - Fator A (temperatura): } 0,16 \mathrm{~ns} ; & \text { IVG - Fator A (temperatura): } \\
\text { Fator B (substrato): } 4,21^{* *} \text {; Fator A x B: } & 14,17 * * ; \text { Fator B (substrato): } \\
2,35 \mathrm{~ns} ; \mathrm{CV}: 13,33 \% & \mathrm{~ns} ; \mathrm{CV}: 17,50 \%\end{array}$} \\
\hline \multicolumn{7}{|c|}{$\begin{array}{l}\text { ns - valor não significativo pelo teste } \mathrm{F} \text { a } 5 \% \text { de probabilidade. Médias } \\
\text { seguidas pela mesma letra minúscula, na linha, e maiúscula, na coluna, } \\
\text { não diferem entre si pelo teste Tukey a } 5 \% \text { de probabilidade. CV- } \\
\text { coeficiente de variação. *Substratos: SV- sobre vermiculita; SP- sobre } \\
\text { papel; SA- sobre areia; EV- entre vermiculita; EP- entre papel e EA- } \\
\text { entre areia. }\end{array}$} \\
\hline
\end{tabular}

As sementes de cedro não apresentaram, para valores de germinação (Tabela 3), diferenciação estatística para as temperaturas e os substratos testados. Para os valores de IVG, observou-se que houve uma maior velocidade de germinação para as sementes mantidas à $25^{\circ} \mathrm{C}$, e dentro desta temperatura, o substrato sobre areia foi superior ao sobre papel, embora o primeiro não diferisse estatísticamente dos outros tratamentos.

A interação entre os fatores testados, temperatura e substrato, para o cedro (Tabela 3) só existiu para o parâmetro IVG. Indicando que a velocidade de germinação das sementes, dentro de cada substrato variou conforme a temperatura testada. Com relação aos valores de CV, estes foram baixos (GOMES, 1987) para esta espécie, ou seja, 6,22\% para germinação e 5,64\% para IVG.
Levando em conta as caracteristicas externas das sementes como: forma, tamanho, textura e cor (FIGLIOLIA et al., 1993; FERRAZ; CALVI, 2010) e as dos substratos, quando são considerados: custo, reaproveitamento, nível de contaminação e capacidade de retenção de água entre outros (PIÑA-RODRIGUES; VIEIRA， 1988; FIGLIOLIA; PIÑA-RODRIGUES， 1995; BRASIL, 2009), procurou-se assim sugerir os tratamentos mais adequados dentro dos resultados obtidos para cada uma das espécies testadas.

Tabela 3. Germinação (\%) e índice de velocidade de germinação (IVG) de sementes de Cedrela fissilis (cedro) submetidas a duas temperaturas $\left(25\right.$ e $\left.20-30^{\circ} \mathrm{C}\right)$ e seis substratos*

\begin{tabular}{|c|c|c|c|c|c|c|}
\hline \multirow[b]{2}{*}{ Tratamentos } & \multicolumn{3}{|c|}{$\% \mathrm{G}$} & \multicolumn{3}{|c|}{ IVG } \\
\hline & $25^{\circ} \mathrm{C}$ & $20-30^{\circ} \mathrm{C}$ & Média & $25^{\circ} \mathrm{C}$ & $20-30^{\circ} \mathrm{C}$ & Média \\
\hline SV & 99 & 99 & $99 \mathrm{~A}$ & $3,47 \mathrm{ABa}$ & $2,59 \mathrm{Ab}$ & $3,03 \mathrm{~A}$ \\
\hline SP & 100 & 100 & $100 \mathrm{~A}$ & $3,27 \mathrm{Ba}$ & $2,82 \mathrm{Ab}$ & $3,05 \mathrm{~A}$ \\
\hline SA & 98 & 97 & $98 \mathrm{~A}$ & 3,69 Aa & $2,70 \mathrm{Ab}$ & $3,20 \mathrm{~A}$ \\
\hline EV & 100 & 100 & $100 \mathrm{~A}$ & $3,41 \mathrm{ABa}$ & $2,86 \mathrm{Ab}$ & $3,14 \mathrm{~A}$ \\
\hline $\mathrm{EP}$ & 99 & 97 & $98 \mathrm{~A}$ & $3,39 \mathrm{ABa}$ & $2,83 \mathrm{Ab}$ & $3,11 \mathrm{~A}$ \\
\hline EA & 98 & 98 & $98 \mathrm{~A}$ & $3,45 \mathrm{ABa}$ & $2,88 \mathrm{Ab}$ & $3,17 \mathrm{~A}$ \\
\hline Média & 99 a & $99 \mathrm{a}$ & & \multicolumn{3}{|c|}{$2,78 \mathrm{~b}$} \\
\hline \multicolumn{4}{|c|}{$\begin{array}{l}\% \mathrm{G} \text { - Fator A (temperatura): } 0,62 \mathrm{~ns} \text {; Fator B } \\
\text { (substrato): } 1,54 \mathrm{~ns} \text {; Fator A x B: } 0,17 \mathrm{~ns} \text {; } \\
\text { CV: } 6,22 \%\end{array}$} & $\begin{array}{l}\text { IVG - Fat } \\
173,38 * * ; \\
1,09 \mathrm{~ns} ; \text { Fat } \\
5,64 \%\end{array}$ & $\begin{array}{l}\text { A }(\text { tem } \\
\text { Fator B } \\
\text { A } x \text { B: } 2\end{array}$ & $\begin{array}{l}\text { ratura): } \\
\text { ostrato): } \\
\text { * ; CV: }\end{array}$ \\
\hline \multicolumn{7}{|c|}{$\begin{array}{l}\text { ns - valor não significativo pelo teste } \mathrm{F} \text { a } 5 \% \text { de probabilidade. Médias seguidas } \\
\text { pela mesma letra minúscula, na linha, e maiúscula, na coluna, não diferem entre si } \\
\text { pelo teste Tukey a } 5 \% \text { de probabilidade. CV- coeficiente de variação. *Substratos: } \\
\text { SV- sobre vermiculita; SP- sobre papel; SA- sobre areia; EV- entre vermiculita; } \\
\text { EP- entre papel e EA- entre areia. }\end{array}$} \\
\hline
\end{tabular}

Analisando as caracteristicas da semente como a sua forma e a coloração do tegumento, além do ambiente onde cada espécie ocorre, são feitas algumas considerações sobre os melhores substratos, em função dos resultados obtidos, dentro dos respectivos ensaios. Ao final de cada análise são sugeridos um ou mais substratos, os mais 
adequados, considerando que o seu uso atende as caracteristicas da semente e/ou do local de ocorrência da espécie.

As sementes de Astronium graveolens (guaritá), família Anacardiaceae, se apresentam compridas e estreitas, com um tamanho médio de 3,0 x 10,0 mm, em um formato oblongo e roliço e uma coloração marrom escura. Considerando que os substratos testados (areia, papel e vermiculita) podem ser indicados; dois deles são os mais adequados, a areia e a vermiculita, pois acomodam melhor as sementes desta espécie em razão do seu formato. $\mathrm{O}$ uso da areia e da vermiculta, dificulta o deslocamento e o agrupamento das sementes diminuindo as chances de contaminação entre estas. $\mathrm{O}$ mesmo não ocorre após a colocação das sementes tanto sobre como entre papel, pois a sua tendencia é se agruparem. A maior área de contato entre o tegumento e o substrato, melhora também a absorção de água pela semente. Deste modo, o tamanho da área de contato entre o substrato umedecido e a semente propicia que quanto maior esta área, maior será a germinação total e menor o tempo necessário para que ela seja alcançada (CARNEIRO; GUEDES, 1992).

Com relação a coloração das sementes, a avaliação pode ser um pouco prejudicada em relação a estes dois substratos (areia e vermiculita) pois quando estão úmidos dificultam a localização das sementes dentro do gerbox, mas a vantagem de não se contaminar as sementes pelo agrupamento das mesmas compensa esta dificuldade.

Considerando o ambiente onde a espécie ocorre, o guaritá segundo Lorenzi (1992) aparece em terrenos rochosos e secos, e deste modo o substrato areia reproduz melhor esta condição em relação a vermiculita, pois este substrato tem como característica a desuniformidade na retenção e distribuição da água, uma vez que a água tende a se depositar na parte inferior do substrato (FERRAZ; CALVI, 2010), ficando portanto a parte superior mais seca. A análise é válida mesmo na modalidade entre semeadura (onde apresentou bons resultados), desde que ela seja rasa, ou seja as sementes estejam recobertas com uma fina camada de areia. Ainda segundo Lorenzi (1992) e Lopes et al. (2012) esta espécie é indiferente a luz, e os resultados de germinação e IVG confirmam esta indiferença, pois tanto a semeadura sobre como a entre os substratos testados apresentaram bons resultados.

As sementes de Cytharexyllum myrianthum (pau-viola), família verbenaceae, são oblongas e encurvadas, com amendoas bipartidas, dimensão aproximada de 0,4 x $10,0 \mathrm{~mm}$ e cor bege claro. Dois substratos, sobre papel e sobre areia, foram considerados os melhores para o parâmetro IVG (Tabela 2), que melhor definiu os tratamentos testados, indicando que a semeadura sobre substrato é favorecida em função da espécie ser considerada heliófita (LORENZI, 1992). 
Estes substratos também apresentaram os dois maiores valores médios de germinação.

Com base no formato das sementes e por ser o pau-viola uma espécie higrófita (LORENZI, 1992), o tratamento sobre areia, apresenta mais vantagens em relação ao sobre papel, pois a área de absorção de água pela semente aumenta e também deixa de existir a possibilidade das sementes se agruparem, diminuindo a contaminação destas; um outro ponto favoravel ao substrato areia é apresentar uma baixa contaminação por microorganismos, sendo recomendado o uso com espécies florestais (FIGLIOLIA et al, 1993; PIÑA-RODRIGUES et al., 2004). A coloração das sementes, bege claro, não se sobressai nos substratos umedecidos (areia e papel), mas como observado anteriormente, esta condição não é tão importante quanto manter as sementes separadas, como é possivel na areia, para evitar a contaminação.

As sementes de Cedrela fissilis (cedro), família Meliaceae, são achatadas e aladas, com dimensões aproximadas de 5,0 x $10,0 \mathrm{~mm}$ (sem asa) e $35 \times 15 \mathrm{~mm}$ (com asa) e com coloração marrom claro. Mas para a realização dos ensaios as alas foram retiradas. Os tratamentos testados com esta espécie foram equivalentes estatisticamente, tanto para a germinação como para o IVG (Tabela 3), estes resultados levando em consideração o tipo de semeadura realizado (entre e sobre substrato), confirmam a informação que a semente desta espécie é indiferente a luminosidade para germinar (LORENZI, 1992; FIGLIOLIA et al., 2006).

Considerando a forma (FIGLIOLIA et al.,1993; FIGLIOLIA; PIÑA-RODRIGUES, 1995) da semente de C. fissilis a semeadura destas no substrato papel também é indicada, deste modo, todos os tratamentos testados podem ser utilizados. Porem quando são anlisadas as caracteristicas dos substratos, o comportamento da espécie em campo (prefere solos profundos e úmidos de acordo com Lorenzi, 1992) e os resultados obtidos no ensaio (Tabela 3), tem-se então que a semeadura em areia nas duas modalidades e entre vermiculita, apresentam os maiores valores de IVG (embora não difiram estatisticamente de outros tratamentos), sendo que a indicação pela vermiculita apresenta mais vantagens, pois além da alta retenção de umidade facilitando a absorção de água pela semente, este substrato apresenta também baixo peso e baixa contaminação por microorganismos (FIGLIOLIA; PIÑARODRIGUES, 1995; FERRAZ; CALVI, 2010).

As colorações da semente de cedro e do substrato vermiculita umedecido, podem difcultar as contagens, em razão da semelhança de cores, mas a semeadura em vermiculita impede o agrupamento das sementes ao longo do período do ensaio, evitando a contaminação das sementes dentro do gerbox. Esta caracteristica (manter o espaçamento de semeadura) se sobressai em 
relação as dificuldades que a outra caracteristica (semelhança de cores entre tegumento e substrato) pode proporcionar.

Ainda cabe a observação que a semente de $C$. fissilis mesmo tendo respostas equivalentes para a germinação e velocidade de germinação (IVG), em todos os substratos testados (areia, papel e vermiculita) nas duas modalidades de semeadura, e mesmo sabendo que uns se mantém mais úmidos (vermiculita) que outros (papel e areia) e que a espécie prefere solos úmidos, uma provavel razão para os substratos testados terem se comportado por igual é porque o umedecimento do ensaio, durante todo o período, foi realizado corretamente, suprindo as deficiências (dos substratos) já mencionadas anteriormente. Por este motivo é interessante indicar a vermiculita, pois caso se tenha uma irrigação do substrato deficiente durante o período de ensaio (e sendo a espécie exigente em umidade), a vermiculita pode compensar esta falha, o papel, por exemplo, já não compensaria (ele secaria rapidamente).

\section{CONCLUSÕES}

- Astronium graveolens (guaritá): para dados de germinação não houve diferença entre temperaturas e substratos; para o IVG não se observou diferenças entre as temperaturas e os melhores substratos foram sobre areia, sobre vermiculita, entre areia, entre vermiculita e entre papel.
- Cytharexyllum myrianthum (pau-viola): para dados de germinação e IVG não houve diferenciação entre as temperaturas. Com relação aos substratos, somente entre areia foi diferente estatisticamente da semeadura sobre areia considerando o percentual de germinação; para o IVG os melhores tratamentos foram sobre papel e sobre areia.

- Cedrela fissilis (cedro): as temperaturas variaram somente para o IVG, sendo $25^{\circ} \mathrm{C}$ a melhor temperatura. Para os substratos não houve diferenciação estatistica nos dois parâmetros testados.

\section{REFERÊNCIAS}

ALVES E.U., PAULA R.C., OLIVEIRA A.P., BRUNO R.L.A., DINIZ A.A. Germinação de sementes de Mimosa caesalpiniaefolia Benth. em diferentes substratos e temperaturas. Revista Brasileira de Semente, Londrina, v.24, n.1, p.169-178, 2002. $\quad$ http://dx.doi.org/10.1590/S0101$\underline{31222002000100025}$

BORGES E.E.L., RENA A.B. Germinação de sementes. In: Aguiar IB, Piña-Rodrigues FCM, Figliolia MB, coordenadores. Sementes florestais tropicais. Brasília: ABRATES; 1993. p. 83-135.

BRASIL. Ministério da Agricultura, Pecuária e Abastecimento. Regras para análise de sementes. Brasília: MAPA/ACS, 2009. 395p. 
http://www.bs.cca.ufsc.br/publicacoes/regras

\%20analise \%20sementes.pdf

CARNEIRO J.W.P., GUEDES T.A. Influência do contato das sementes de stevia (Stevia rebaudiana (Bert.) Bertoni) no substrato avaliada pela função de Weibull. Revista Brasileira de Sementes, Brasília, v.14, n.1, p.65-68, 1992.

\section{CARVALHO N.M., NAKAGAWA J.} Sementes: ciência, tecnologia e produção. Jaboticabal: FUNEP; 2000. 588p.

FERRAZ I.D.K., CALVI G.P. Teste de germinação. In: Lima Junior MJV, coordenador. Manual de procedimentos de análise de sementes florestais. Londrina: Abrates; $2010 . \quad$ p.5.1-5.36. http://www.ufvjm.edu.br/disciplinas/agr058/fi les/2013/06/Manual-de-An\%C3\%A1lise-de-

$\underline{\text { Sementes-Florestais.pdf }}$

FIGLIOLIA M.B., AGUIAR I.B., SILVA A. Germinação de sementes de Lafoensia glyptocarpa Koehne (mirindiba-rosa), Myroxylon peruiferum L. f. (cabreúvavermelha) e Cedrela fissilis Vell. (cedrorosa). Revista do Instituto Florestal, São Paulo, v.18, n. único, p.49-58, 2006.

http://www.iflorestal.sp.gov.br/publicacoes/re vista_if/rev18-unicopdf/RIF18.pdf
FIGLIOLIA M.B., OLIVEIRA E.C., PIÑARODRIGUES F.C.M. Análise de sementes. In: AGUIAR I.B., PIÑA-RODRIGUES F.C.M. \& FIGLIOLIA M.B., (eds.). Sementes florestais tropicais. Brasília: ABRATES; 1993. p.137-174.

FIGLIOLIA M.B., PIÑA-RODRIGUES F.C.M. Considerações práticas sobre o teste de germinação. In: SILVA A., PIÑARODRIGUES F.C.M., FIGLIOLIA M.B. (eds.). Manual técnico de sementes florestais. São Paulo: Instituto Florestal, 1995. p.45-59. (Série Registros, 14).

GOMES F.P. Curso de estatística experimental. Piracicaba: Nobel, 1987. 467p.

LABOURIAU L.G. A germinação da semente. Washington, D.C.: Secretaria Geral da Organização dos Estados Americanos, 1983. 173p.

LIMA JUNIOR M.J.V. Manual de procedimentos para análise de sementes florestais. Manaus: UFAM, 2010. 146p. http://www.ufvjm.edu.br/disciplinas/agr058/fi les/2013/06/Manual-de-An\%C3\%A1lise-de-

$\underline{\text { Sementes-Florestais.pdf }}$

LOPES A., ROSA-OSMAN S.M., PIEDADE M.T.F. Caracterização morfológica das plântulas de cinco espécies arbóreas da floresta estacional semidecidual, Brasil. Revista Floresta, Curitiba, v.42, n.1, p.5-114. 
2012.

http://ojs.c3sl.ufpr.br/ojs2/index.php/floresta/ article/view/26306/17506

LORENZI, H. Árvores brasileiras: manual de identificação e cultivo de plantas arbóreas nativas do Brasil. Nova Odessa: Editora Plantarum; 1992. 352p.

MAGUIRE J.D. Speed of germination-aid in selection and evaluation for seedling emergence and vigor. Crop Science, Madison, v.2, n.1, p.176-177, 1962.

MEDEIROS A.C.S., ABREU D.C.A. Instruções para testes de germinação de sementes florestais nativas da mata atlântica. Colombo: EMBRAPA-CNPF; 2005. (EMBRAPA-CNPF. Comunicado Técnico, 151).

http://www.cnpf.embrapa.br/publica/comunte c/edicoes/com_tec151.pdf

MONDO V.H.V., CARVALHO S.J.P., DIAS A.C.R., MARCOS FILHO J. Efeitos da luz e temperatura na germinação de sementes de quatro espécies de plantas daninhas do gênero Digitaria. Revista Brasileira de Sementes, Londrina, v.32, n.1, p.131-137, 2010. http://www.scielo.br/pdf/rbs/v32n1/v32n1a15 .pdf

PACHECO M.V., MATOS V.P., FERREIRA R.L.C., FELICIANO A.L.P., PINTO K.M.S.
Efeito de temperaturas e substratos na germinação de sementes de Myracrodruon urundeuva Fr. All. (Anacardiaceae). Revista Árvore, Viçosa, v.30, n.3, p.359-367, 2006. http://www.scielo.br/pdf/rarv/v30n3/a06v30n 3.pdf

PIÑA-RODRIGUES F.C.M., FIGLIOLIA M.B., PEIXOTO M.C. Testes de qualidade. In: Ferreira AG, Borghetti F, coordenadores. Germinação: do básico ao aplicado. Porto Alegre: Artmed; 2004. p.283-297.

PIÑA-RODRIGUES F.C.M., VIEIRA J.D. Teste de germinação. In: Piña-Rodrigues FCM, coordenadora. Manual de análise de sementes florestais. Campinas: Fundação Cargill; 1988. p.70-90.

POPINIGIS F. Fisiologia da semente. Brasília: AGIPLAN; 1977. 289p.

SANTOS S.R.G., AGUIAR I.B. Germinação de sementes de branquilho (Sebastiania commersoniana (Baill.) Smith \& Downs) em função do substrato e do regime de temperatura. Revista Brasileira de Sementes, Brasília, v.22, n.1, p.120-126, 2000.

WIELEWICKI A.P., LEONHARDT C., SCHLINDWEIN G., MEDEIROS A.C.S. Proposta de padrões de germinação e teor de água para sementes de algumas espécies florestais presentes na região sul do Brasil. 
Revista Brasileira de Sementes, Pelotas,

v.28, n.3, p.191-197, 2006.

http://www.scielo.br/pdf/rbs/v28n3/27.pdf 